\title{
Stochastic Model for Magazine Retailer Problem
}

\author{
Endang Julivia Pakpahan ${ }^{1}$, Roland T. H Siagian ${ }^{2}$, Sari Dewi Nasution ${ }^{3}$ \\ ${ }^{1,2,3}$ Department of Mathematics, University of North Sumatera, Indonesia
}

\begin{abstract}
In this paper magazine retailer model extensions are developed. These two extensions allow modelling of the situations where there are certain percentage of customers who are willing to wait for the next regular order. The first model assumes that it is possible to identify customers who are willing to wait for the next regular order at the beginning of planning period, while the second model assumes back order option at time when stock out occurs.
\end{abstract}

Keywords: Inventory, Magazine Retailer Model, Stochastic Model.

\section{Introduction}

There are a number of logistics systems and cases in which orders may be placed only at certain times. Ordering dates of these systems are known in advance, because they are imposed by some limitations of the logistics system itself, or are due to the specific characteristics of the products kept on stock. Objective of inventory control, in these systems, is to determine the number of orders that will be sufficient to cover demand between two consecutive orders. Ordering too little, in these systems and cases, means that a demand cannot be satisfied, and additional costs will occur, such as additional order costs, lost sales costs, reputation and business credibility loss, future contracts and sales loss, etc. Ordering too much, means the occurrence of excessive inventory levels, that generate costs whose values depends on the nature of the product. Modeling of described inventory control problems can be successfully done using magazine retailer model and its extensions.

\section{Literature Review}

Magazine retailer problem has been presenting the literature for over 100 years [1], and magazine retailer model that solves magazine retailer problem is one of the most famous models in the operating management and operational research, in general [2]. This model, even if introduced in the middle of the last century [3], still attracts the attention of a large number of authors in recent years [4]. Widespread of magazine retailer problems and magazine retailer model popularity have resulted in numerous articles dealing exclusively with taxonomy of magazine retailer model extensions, or articles exclusively dealing only with literature reviews in this filed [4,5,6,7].Applicability of magazine retailer model is manifold. Inventories in the food and the clothing industry are often modeled using magazine retailer model [8]. Magazine retailer model is also used in modelling and solving problems in the production capacity management, and in service industries, such as airline and hotel reservations $[9,10]$. As the lifetime of the product continues to shorten, the importance of the magazine retailer models grows, so many magazine retailer model extensions are developed in the last few years [4,11,12].

\section{The Magazine Retailer Model}

In this chapter we discuss the problem of controlling the inventory of a single item with stochastic demands over a single period. This problem is also known as the Magazine retailer Problem because the prototype is the problem faced by a magazine retailer trying to decide how many newspapers to stock on a newsstand before observing demand. The magazine retailer faced both overage and underage costs if he orders too much or if he orders too little. The Magazine retailer Problems is therefore the problem of deciding the size of a single order that must be placed before observing demand when there are overage and underage costs. The problem is particularly important for items with significant demand uncertainty and large overage and underage costs.

Let $D$ denote the one period random demand, with mean $\mu=$ $E[D]$ and variance $\sigma^{2}=V[D]$. Let $c$ be the unit cost, $p>c$ the selling price and $s<c$ the salvage value. If $Q$ units are ordered, then $\min (Q ; D)$ units are sold and $(Q-D)^{+}=\max (Q-$ $D ; 0)$ units are salvaged. The profit is given by $p \min (Q ; D)$ $+s(Q-D)^{+}-c Q$. The expected profit is well defined and given by:

$$
\pi Q)=p E \min (Q ; D)+s E(Q-D)^{+}--c Q:
$$

Using the fact that $\min (Q ; D)=D-(D-Q)+$ we can write the expected profit as

$$
\pi(\mathrm{Q})=(\mathrm{p}-\mathrm{c}) \mu-\mathrm{G}(\mathrm{Q})
$$

where

$$
G(Q)=(c-s) E(Q-D)^{+}+(p-c) E(D-Q)^{+} \geq 0:
$$

Let $h=c-s$ and $b=p-c$. It is convenient to think of $h$ as the per unit overage cost and of $b$ as the per unit underage cost. Sometimes the underage cost is inflated to take into account the ill-will cost associated with unsatisfied demand.

Equation (1) allow us to view the problem of maximizing $\pi Q)$ as that of minimizing the expected overage and underage cost $G(Q)$.

Let $G^{\text {det }}(Q)=h(\mu-Q)^{+}+b(Q-\mu)^{+}$. This represents the cost when $D$ is deterministic, i.e., $\operatorname{Pr}(D=\mu)=1$. Clearly $Q=\mu$ minimizes $\mathrm{G}^{\text {det }}(Q)$ and $\mathrm{G}^{\text {det }}(\mu)=0, \mathrm{~s} \mathrm{o}^{\text {det }}(\mu)=(p-c) \mu$. Thus, the Magazine retailer Problem is only interesting when demand is random. Notice that the problem also becomes trivial when $s=c$ for in this case we can order an infinite amount, satisfy all demand, and then return all unsold items.

Let $g(x)=h x^{+}+b x^{-}$, then $G(Q)$ can be written as $G(Q)=$ $E[g(Q-D)]$. Since $g$ is convex and convexity is preserved by 


\section{International Journal of Science and Research (IJSR) \\ ISSN (Online): 2319-7064 \\ Index Copernicus Value (2013): 6.14 | Impact Factor (2014): 5.611}

linear transformations and by the expectation operator it follows that $G$ is also convex. By Jensen's inequality $G(Q)$ $\geq G^{\text {det }}(Q)$. As a result, $\pi(Q) \leq \pi^{\text {det }}(Q) \leq \pi^{\text {det }}(\mu)=(p-c) \mu$. Thus, the expected pro ${ }^{-}$is lower than it would be in the case of deterministic demand. If the distribution of $D$ is continuous, we can ${ }^{-}$nd an optimal solution by taking the derivative of $G$ and setting it to zero. Since we can interchange the derivative and the expectation operators, it follows that $G^{\prime}(Q)=h E \delta(Q-D)-b E \delta(D-Q)$ where $\delta(x)=1$ if $x>0$ and zero otherwise. Since $E \delta(Q-D)=\operatorname{Pr}(Q-D>0)$ and $E \delta(D$ $Q)=\operatorname{Pr}(D-Q>0)$, it follows that

$$
G^{\prime}(Q)=h \operatorname{Pr}(Q-D>0)-b \operatorname{P~} r(D-Q>0) \text { : }
$$

Setting the derivative to zero reveals that

$$
F(Q) \equiv \operatorname{Pr}(D \leq Q)=\frac{b}{b+h}=\frac{p-c}{p-8} \equiv \beta .
$$

If $F$ is continuous then there is at least one $Q$ satisfying Equation (2). We can select the smallest such solution by letting

$$
Q^{*}=\inf \{Q \geq 0: F(Q) \geq \beta\} .
$$

It is clear that $Q^{*}$, selected this way, is increasing in $\beta$ and therefore it is increasing in $b$ and decreasing in $h$.

If $F$ is strictly increasing then $F$ has an inverse and there is a unique optimal solution given by

$$
Q^{*}=F^{-1}(\beta) \text {. }
$$

In practice, $D$ often takes values in the set of natural numbers $N=\{0,1, \ldots\}$. In this case it is useful to work with the forward difference $\Delta G(Q)=G(Q+1)-G(Q), Q \epsilon N$. By writing

It is easy to see that

$$
E(D-Q)^{+}=\sum_{j=Q}^{\infty} \operatorname{Pr}(D>j),
$$

$$
\Delta G(Q)=h-(h+b) \operatorname{Pr}(D>Q)
$$

is non-decreasing in $Q$, and that $\lim Q \rightarrow \infty \Delta G(Q)=h>0$, so an optimal solution is given by $Q=\min \{Q \epsilon N: \Delta G(Q) \geq 0\}$, or equivalently,

$$
Q^{*}=\min (Q \in N: F(Q) \geq \beta\} \text {, }
$$

The origin of the Magazine retailer model appears to date back to the 1888 paper by Edgeworth [2] who used the Central Limit Theorem to determine the amount of cash to keep at a bank to satisfy random cash withdrawals from depositors with high probability. The fractile solution (2) appeared in 1951 in the classical paper by Arrow, Harris and Marchak [1].

The magazine retailer solution can be interpreted as providing the smallest supply quantity that guarantees that all demand will be satisfied with probability at least $100 \beta \%$. Thus, the profit maximizing solution results in a service level $100 \beta \%$. In practice, managers often specify $\beta$ and then and $Q$ accordingly. This service level should not be confused with the fraction of demand served from stock, or fill-rate, which is defined as $\alpha=E \min (D ; Q) / E D$.

\section{Normal Demand Distribution}

An important special case arises when the distribution $D$ is normal. The normal assumption is justified by the Central Limit Theorem when the demand comes from many different independent or weakly dependent customers. If $D$ is normal, then we can write $D=\mu+\sigma Z$ where $Z$ is a standard normal random variable. Let $\phi(z)=\operatorname{Pr}(Z \leq z)$ be the cumulative distribution function of the standard normal random variable. Although the function (C) is not available in closed form, it is available in tables and also in electronic spreadsheets. Let $z_{\beta}=\phi^{1}(\beta)$. In Microsoft Excel, for example, the command NORMSINV(0.75) returns 0.6745 so $z: 75=$ $0: 6745$. Since $\operatorname{Pr}(D \leq \mu+z \beta \sigma)=\phi\left(\mathrm{z}_{\beta}\right)=\beta$, it follows that

$$
Q^{*}=\mu+z_{\beta} \sigma
$$

Satifies Equation (4), so Equation (6) gives the optimal solution for the case of normal demand. The quantity $z \beta$ is known as the safety factor and $Q^{*}-\mu=z \beta \sigma$ is known as the safety stock. It can be shown that

$$
E\left(D-Q^{*}\right)^{+}=\sigma E\left(Z-z_{\beta}\right)^{+}=\sigma\left[\phi\left(z_{\beta}\right)-(1-\beta) z_{\beta}\right]
$$

where $\phi$ is the density of the standard normal random variable. As a consequence,

$$
\begin{aligned}
G\left(Q^{*}\right) & =h E\left(Q^{*}-D\right)^{+}+b E\left(D-Q^{*}\right)^{+} \\
& =h\left(Q^{*}-\mu\right)+(h+b) E\left(D-Q^{*}\right)^{+} \\
& =h z_{\beta} \sigma+(h+b) \sigma E\left(Z-z_{\beta}\right)^{+} \\
& =h z_{\beta} \sigma+(h+b) \sigma\left[\phi\left(z_{\beta}\right)-(1-\beta) z_{\beta}\right] \\
& =(h+b) \sigma \phi\left(z_{\beta}\right),
\end{aligned}
$$

So

$$
\begin{aligned}
\pi\left(Q^{*}\right) & =(p-c) \mu-(h+b) \sigma \phi\left(z_{\beta}\right) \\
& =(p-c) \mu-(p-s) \sigma \phi\left(z_{\beta}\right) .
\end{aligned}
$$

$$
\begin{aligned}
& \text { In addition, since } E \min \left(D, Q^{*}\right)=E D-E\left(D-Q^{*}\right)^{+} \text {, we can divide by } E D \text { and write the fill-rate } \\
& \qquad \alpha=1-\operatorname{cr}\left[\phi\left(z_{\beta}\right)-(1-\beta) z_{\beta}\right]
\end{aligned}
$$

where $\mathrm{cv}=\sigma / \mu$ is the coefficient of variation of demand. Since $\phi(z \beta)-(1-\beta) z \beta \geq 0$ is decreasing in $\beta$, it follows that the $\alpha$ is increasing in $\beta$ and decreasing in cv. Numerical results show that $\alpha \geq \beta$ for all reasonable values of $\mathrm{cv}$, including $\mathrm{cv} \leq$ $1 / 3$, which is about the highest $c v$ value for which the normal model is appropriate. Notice, for example, that $\alpha=$ $97 \%$ when $\beta=75 \%$ and $\mathrm{cv}=0: 2$, while $\alpha=99: 1 \%$ when $\beta=$ $90 \%$ and $\mathrm{cv}=0: 2$.

Example Normal Demand: Suppose that $D$ is normal with mean $\mu=100$ and standard deviation $\sigma=20$. If $c=5, h=1$ and $b=3$, then $\beta=0: 75$ and $Q^{*}=100+0: 6745 * 20=$ 113,49 . Notice that the order is for 13.49 units (safety stock) more than the mean. Typing NORMDIST(.6574,0,1,0) in Microsoft Excel, returns $\phi(.6745)=0.3178$ so $G(113.49)=4$ $* 20 * .3178=25.42$, and $\pi(113.49)=274.58$, with $\alpha=97 \%$.

\section{Illustrative examples}




\section{International Journal of Science and Research (IJSR) \\ ISSN (Online): 2319-7064}

Index Copernicus Value (2013): 6.14 | Impact Factor (2014): 5.611

Magazine Retailer Problem

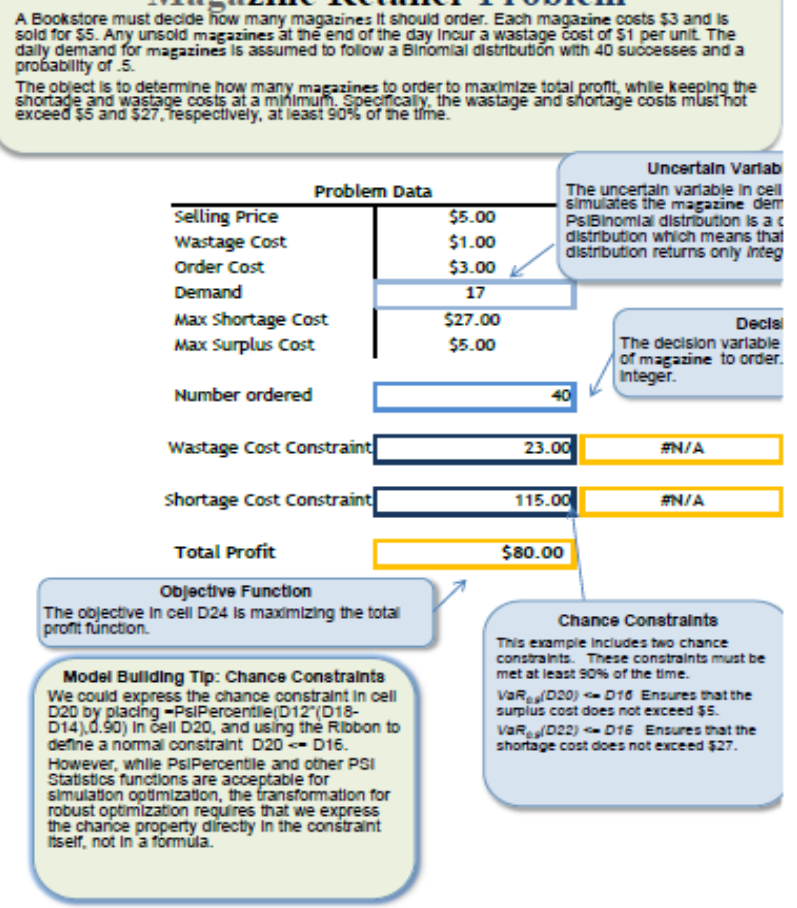

\section{Conclusion}

Derived extensions of magazine retailer model with backorder option are models that allow achieving the same service level with lower inventory levels in the case when there is a percentage of customers willing to wait for the next regular order. In situations where there are no buyers who are willing to wait for the next order, than these situations can be successfully modelled with developed extensions, where developed extensions become a classic magazine retailer model. In situations where there are buyers who are willing to wait for the next regular order, magazine retailer model with backorder option, that is triggered after the stock out, is more efficient than the classic magazine retailer model, and the magazine retailer model with backorder option, that is triggered at the beginning of the planning period, is more efficient than both models. In situations where all customers are willing to wait for the next regular order, both extensions of the magazine retailer model developed in this paper, will give the same result. Developed extensions could be even more efficient if they could enable modelling the percentage of customers who are not willing to wait for the next regular order, but are willing to wait for emergency order.

\section{References}

[1] Edgeworth, F.Y., 1888. The Mathematical Theory of Banking. Journal of the Royal Statistical Society, 53, 113-127.

[2] Hill, A.V., 2010. The Encyclopedia of Operations Management. Minnesota: Clamshell Beach Press. Dostupno http://www.ClamshellBeachPress.com.[Pristupljeno 07.04.2010].

[3] Arrow, K., Harris, T. and Marschak, J., 1951. Optimal Inventory Policy. Econometrica, 19 (3), 250-272.
[4] Khouja, M., 1999. The single-period (news-vendor) problem: literature review and suggestions for future research. Omega, International Journal of Management Science, 27 (5), 537-553.

[5] Gallego, G. and Moon, I., 1993. The distribution free newsboy problem: Review and extensions. Journal of the Operational Research Society, 44 (8), 825-834.

[6] Petruzzi, N. C. and Dada M., 1999. Pricing and the Newsvendor Problem: A Review with Extensions. Operations Research, 47 (2), 183-194.

[7] Nahmias S., 2008. Production and Operations Analysis, 6th ed., New York: Mcgraw-hill/Irwin.

[8] Graves, S.C. and Parsons, J.C.W., 2005. Using a Newsvendor Model for Inventory Planning of NFL Replica Jerseys. In Proc. MSOM Conference, Northwestern University, Evanston, IL.

[9] Weatherford, L.R. and Pfeifer, P.E., 1994. The economic value of using advance booking of orders. Omega, International Journal of Management Science, 22 (1), 105-111.

[10] Van Mieghem, J. A. and Rudi, N., 2002. Newsvendor networks: Inventory management and capacity investment with discretionary activities. Manufacturing and Service Oper. Management, 4(4), 313-335.

[11] Alfares K.H. and Elmorra H.H., 2005. The distributionfree newsboy problem: Extensions to the shortage penalty case. Int. J. Production Economics, 93-94, 465477.

[12]Haji, M., Haji, R. and Darabi, H., 2007. Price Discount and Stochastic Initial Inventory in the Newsboy Problem. Journal of Industrial and Systems Engineering,1 (2), 130-138.

[13] Hadis B., and Edin K. 2013. Newsvendor Extensions with Backorder Option. 17th International Research/Expert Conference "Trends in the Development of Machinery and ATurkey 